\title{
Habitat Evaluation on Scour Hole Downflow Low Drop Structure Types Using Large-Scale Experiment
}

\author{
Joongu Kang, Changsung Kim, Sanghwa Jung, Hongkoo Yeo \\ Department of Water Resource Research, Korea Institute of Construction Technology, Ilsan, Korea \\ Email: jgkang02@kict.re.kr, csckim@kict.re.kr, kikimorah@kict.re.kr, yeo917@kict.re.kr
}

Received June 15, 2012; revised July 14, 2012; accepted July 24, 2012

\begin{abstract}
This study sought to review whether large-scale experimentation can apply to actual rivers concerning the effect of topographical change by scour in the downstream area of natural-type low drop structures on the fish habitat. The large-scale applicability experiment performed in this study installed low drop structures as the study object within the experiment channel and precisely surveyed topography in the downstream area of drop structures along with the hydraulic amount including water level and flow velocity under certain flow conditions. Based on topographical data acquired through the survey after the experiment ended, this study reviewed the change of suitability index and difference of weighted usable area by performing 2D habitat simulation. Ultimately, through the habitat simulation results in cases of considering and not considering scour in the downstream area of drop structures, this study analyzed the effects of topographical change in actual rivers on the habitat.
\end{abstract}

Keywords: Natural Low Drop Structure; Scour; River2D; Fish Habitat; Habitat Suitability Index

\section{Introduction}

The natural river's stability depends on the riverbed slope, silt movement, status of original ground, low channel's depth, structure of channel and riverside, and riverside vegetation. Among these, riverbed slope is the most important factor; thus, a method of properly maintaining riverbed slope should be sought for riverbed stability (H.J. Kim et al. [1]). Mainly installing riverbed maintaining facilities is a universal practice for the natural river's stability. The drop structure as a typical structure of riverbed maintaining facilities is a type of river cross-cutting structure installed to prevent riverbed scour and erosion at the steep slope of a river. The drop structure is generally defined as a structure with sharp fall of $0.5 \mathrm{~m}$ or more. In Korea, installing scour protection structures in the waterspout and downstream area is a universal practice to prevent scouring downstream; most bodies and waterspouts are installed as a single concrete structure (Korea Water Resource Association [2]).

The installation of such drop structure is designed and installed in line with the installation purpose of securing riverbed stability based on the river design standard and is effective for channel stability but is known to cause various ecological and environmental damages such as interruption of the river environment's continuity (H.J. Kim et al. [1]). As a typical example, a river cross-cutting structure at high altitude disrupts the migratory fish's movement between the upstream and downstream areas of a river and reduces the number of fish and diversity of fish species; some fish can also become extinct (Ministry of Environment, MOE [3]). To overcome such demerit, continuing efforts have been made to use natural materials for the body and auxiliary structure of a drop structure or to reduce the ecological and environmental damages by installing fishway at the body of the drop structure, with some achievements. Note, however, that the supplementary methods proposed to date have not presented a fundamental solution. To address the ecological and environmental problems caused by the installation of cross-cutting structures including drop structure, understanding of the living things inhabiting the river in question is essential. Based on such understanding, a most effective method may be to construct a cross-cutting structure through which fish living in the river in question can easily move. Toward this end, precise analysis on the changing hydraulic factor (water depth, velocity, scour, etc.), according to the structure construction and study on how the habitation environment changes should be performed in advance.

Although ecologically disadvantageous, since a river is interrupted because of drop structure installation, such structure installation is also deemed ecologically advantageous in terms of scour and complex flows downstream. Cooper and Knight [4] and the US Washington State Department of Fish and Wildlife [5] suggested that the 
scour generated in the downstream area of structures for artificial slope adjustment, i.e., a drop structure, functions as the fish habitat. Note, however, that they did not present specific habitat evaluation and standard on the size of scour hole (scope, depth, etc.) according to the drop structures. Even though some study achievements have been presented in Korea including the suggestion of low drop structures using huge stones to secure an effective habitat environment, they just presented the standard on the structure's stability. Those studies merely mentioned that the effect of the fish habitat improvement is in the early stages, i.e., citing only water quality improvement (MOE [3]).

The evaluation on the habitat improvement effect in the downstream area of drop structures can be carried out through habitat simulation. The study on habitat began in developed countries including the US, and Europe in the 1970s. In Korea, the concept of river maintaining flow considering fish was adopted only in the latter part of the 1990s, and various studies have been conducted since then (D.G. Lim et al. [6]). Since the 2000s, various types of natural-type drop structures have been suggested to improve the habitat of fish as part of river restoration efforts and have been applied to actual problems. Nonetheless, the studies to date merely present a comprehensive, conceptual result, i.e., the physical habitat can be improved by complex flows through the installation of boulder or embankment within the channel. Actually, systematic and specific studies are insufficient.

This study sought to review whether the reconstruction of the effect of topographical change by scour in the down-stream area of natural-type low drop structures on the habitat in the large-scale channel can apply to an actual river. Concerning the large-scale applicability experiment in this study, a wood drop structure was installed within the experiment channel, the hydraulic amount including water level and flow velocity under certain flux conditions was measured, and the topography in the downstream area of the drop structure was precisely surveyed. Based on topographical data acquired through a survey after the experiment ended, this study reviewed the change of suitability index and difference of weighted usable area by performing 2D habitat simulation. Ultimately, through the habitat simulation results in cases of considering and not considering scour in the downstream area of drop structures, this study analyzed the effects of topographical change in an actual river on the fish habitat.

\section{Hydraulic Model Experiment}

The width of the experiment channel was about $3.2 \mathrm{~m}$, and the maximum experiment flow that could be supplied to the channel was about $8.0 \mathrm{~m}^{3} / \mathrm{s}$. Figure 1 presents the schematics of the V-type drop structure installa-

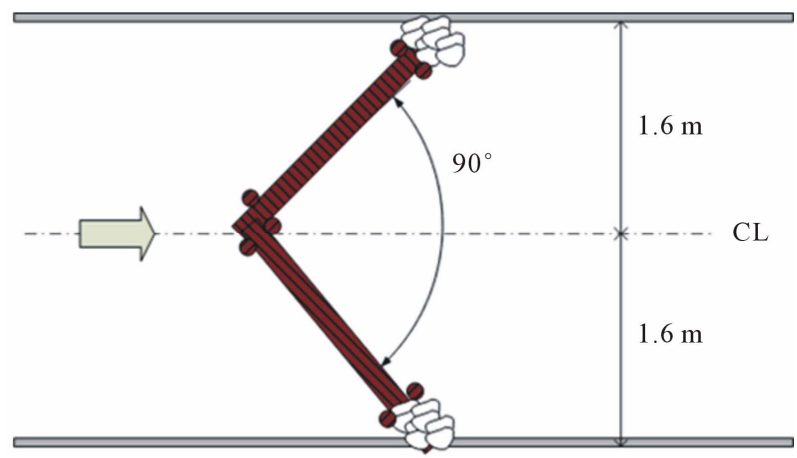

Figure 1. Schematics of V-type drop structure for the verification test.

tion for the large-scale verification test, an upward Vtype drop structure with $0 \%$ cross-cutting slope (horizontal) using wood with diameter of $0.2 \mathrm{~m}$. As for the cross-cutting type drop structure, as a result of indoor experiment, in the case of the up-ward V-type drop structure, similar weighted usable area change was observed regardless of the cross-cutting slope, but horizontal slope was advantageous according to a result of the velocity suitability index. In this context, cutting slope was installed with a horizontal condition considering the onsite conditions in the verification test. With regard to the angle of apex, $140^{\circ}$ was optimum in the evaluation of weighted usable area (WUA), with $70^{\circ}$ exhibiting the minimum WUA; in other angles, WUA was almost similar. In the velocity suitability index, index of 0.8 or more was recorded in the cases of $70^{\circ}-110^{\circ}$. Thus the angle of apex was set as $90^{\circ}$ in the verification test. Figure 2 shows the actual installation of the drop structure. Around the drop structure, a protection hole was installed using river gravel to prevent the loss of structure due to excessive scour. The installation thickness was about $0.05-0.07 \mathrm{~m}$ in case certain riverbed change occurred downstream. Inside of the drop structure embankment, protection was provided using boulders to prevent structure loss and scour caused by flows within the left and right sides. Furthermore, the variation of the wood drop structure in the body of the structure caused by buoyancy was prevented using wooden stakes.

Concerning the test condition, testing was carried out under approximately $0.15 \mathrm{~m}^{3} / \mathrm{s}$ flow condition as shown in Table 1. In the case of water depth downstream, a test was conducted with an outflow condition in the same manner as the indoor test. Hydraulic amount measurement at $10 \mathrm{~m}$ locations in the upstream and downstream areas of the experiment structure was done precisely at 25 measuring points in the upstream and downstream areas consisting of five side lines around the structure; water depth and velocity were measured at each measuring point (Figure 3). For the velocity gauge used for velocity measurement, KENEK's VO-1000, a 1D propeller 

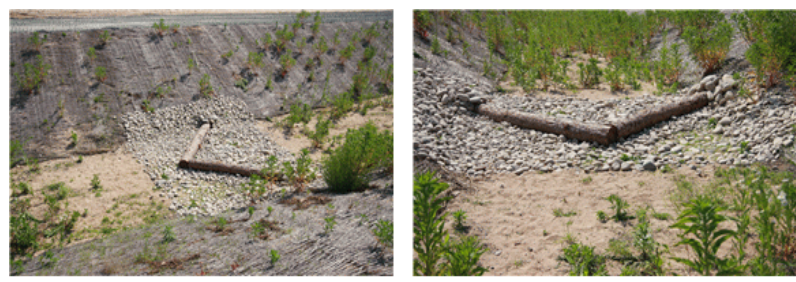

Figure 2. V-type drop structure for the verification test.

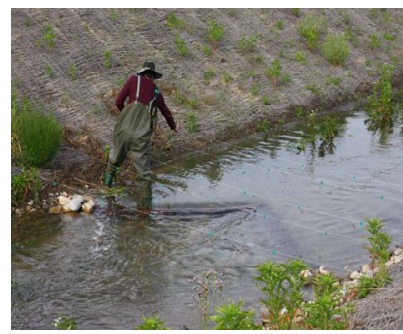

Figure 3. Velocity measurement around the drop structure.

Table 1. Experimental case.

\begin{tabular}{ccccc}
\hline Type & $\begin{array}{c}\text { Discharge } \\
\left(\mathrm{m}^{3} / \mathrm{s}\right)\end{array}$ & $\begin{array}{c}\text { Tail-water } \\
\text { depth }(\mathrm{m})\end{array}$ & $\begin{array}{c}\text { Lateral } \\
\text { slope }(\%)\end{array}$ & $\begin{array}{c}\text { Angle of } \\
\text { apex }\left({ }^{\circ}\right)\end{array}$ \\
\hline H90V00 & 0.15 & 0.20 & 0 & 90 \\
\hline
\end{tabular}

velocity gauge, was used. Through a precision topographical survey before and after the test, topographical change (local scour) was observed around the structure. For the topographical survey, a 3D laser scanner, RIEGL's LMS-Z390i, was used. The 3D laser scanner had topographical interpretation capacity of up to $400 \mathrm{~m}$ and precision of up to $10 \mathrm{~mm}$ (Figure 4). Figure 5 presents the contour map drawn based on the primitive results of surveying the surrounding topography of the drop structure measured using the laser scanner after the hydraulic experiment as the ultimate survey outcome. The topographical survey area was about $20 \mathrm{~m}$ in the longitudinal direction and about $10 \mathrm{~m}$ in the cross-cutting direction centered on the drop structure. The topographical survey points drawn through the precision topographical survey were about 200,000, and topographical data were used as input data of River2D, a 2D habitat evaluation model.

\section{Physical Habitat Evaluation}

Physical habitat evaluation considering riverbed change can be divided into hydraulic simulation, silt movement simulation, and habitat simulation stages as suggested in Figure 6. Although a model that can simulate all the stages exists, it is currently under study; some researchers performed physical habitat evaluations considering riverbed change using commercial programs. This study reviewed the impacts of riverbed change by channel structure on the habitat by linking hydraulic simulation with large-scale model experiments. For hydraulic simu-

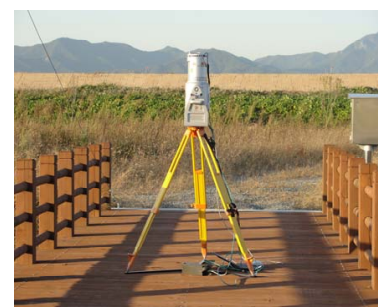

Figure 4. 3D Laser scanner (RIEGL).

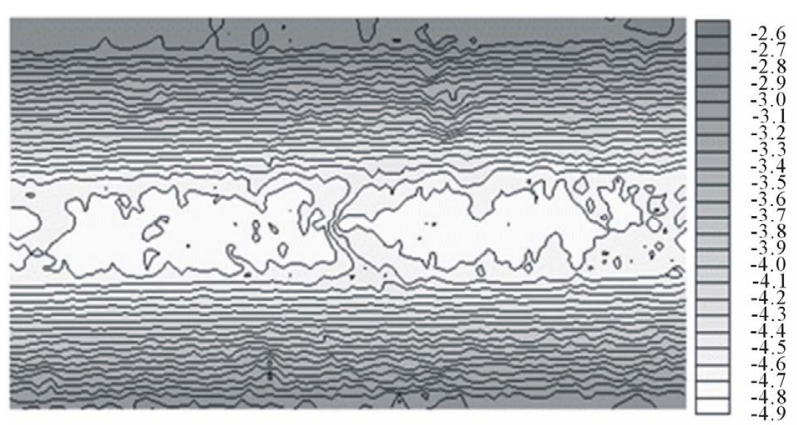

Figure 5. Result of the topographical survey.

lation and habitat simulation, the River2D model developed by Steffler and Blackburn [7] using the PetrovGalerkin finite element method was applied. Data on topographical change according to scour generated by the channel structure was acquired through large-scale model experiments. Through the data, riverbed change could be considered according to the channel structure, and physical habitat evaluation reflecting topographic change could be performed. Svoboda and Russell (2011) [8] conducted a model experiment on scour using large wood structure (LWS) and effects on the habitat. Christopher [9] presented design methods through an analysis of flows and scour features using the 1D model, HECRAS, and 3D model, U2RANS, and conducted a comparative study regarding the field monitoring results. Although physical habitat evaluation in the current channel state can be carried out using physical habitat evaluation models such as the existing PHABSIM and River2D, riverbed change needs to be considered to predict the changes of physical habitat within the channel and the changes by channel structure.

\section{Simulation of Habitat Evaluation}

Habitat simulation in a natural channel has been generally used as a tool to estimate ecology maintaining flow, but this study applied habitat simulation to the structure in question to examine the physical changes of scour in the downstream area of natural-type low drop structures on the fish habitat. Simulation for habitat evaluation was performed based on flow velocity, water depth, and topographical data. Therefore, how the topography of the direct downstream area changes according to natural- 


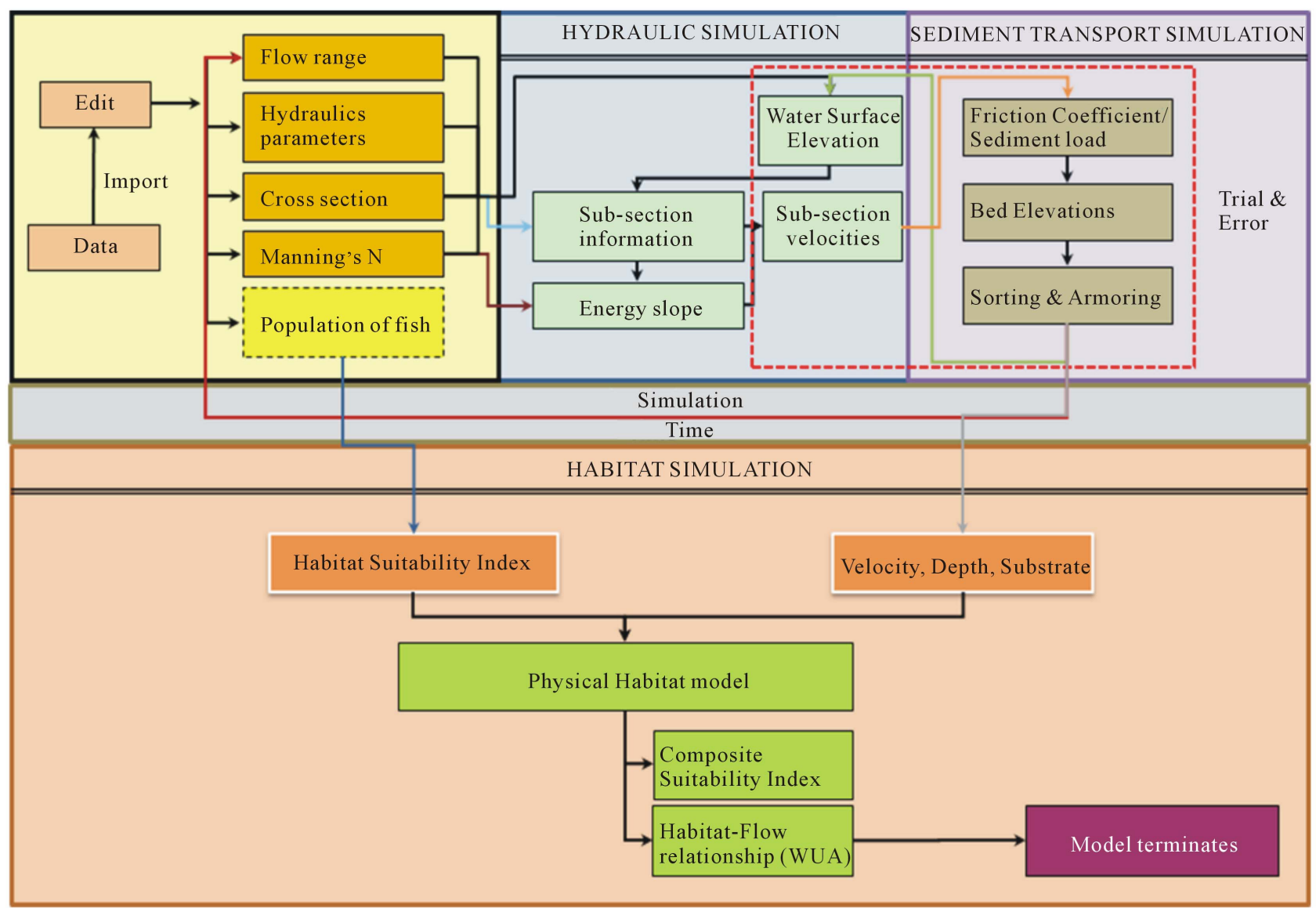

Figure 6. Physical habitat evaluation procedure considering riverbed change.

type low drop structures should be examined in advance. Similar to the previous habitat study cases, simulation was performed in the case wherein scour topography was not considered in the downstream area of structures concerning the habitat simulation conditions. The results were compared with the case of considering scour, and the environmental changes of the habitat within the channel were examined. For habitat simulation, River2D, a 2D habitat model, was used, and boundary conditions and topographical conditions were inputted based on hydraulic experiments. This study simulated a condition that did not consider scour depth in the verification test of hydraulic condition on a large scale, i.e., case wherein scour is perfectly protected and case that did not consider scour depth, and compared these two cases. The topographical data as input data for physical habitat evaluation in the case of considering scour depth in the downstream area of drop structures presented a condition wherein scour was generated and another condition wherein scour was not generated. These two conditions are shown in Figures 7 and 8. The inputted maximum scour depth was $0.22 \mathrm{~m}$, and scour length was about $0.60 \mathrm{~m}$ in the downstream area of the structure.

The advantage/disadvantage of the habitat depends on the types of fish concerned. Therefore, the results can vary according to the selection of fish type, which becomes a very important issue. This study targeted only minnows (Z. platypus). It is rational to examine a variety of fish types, but this study simplified the fish type since the main purpose was to review the environmental changes of scour downstream on the habitat. According to USGS [10], it is possible to use the habitat suitability index drawn in other river basins on the same fish type in an unavoidable case, such as no collection of actual number of fish and lacking survey frequency. According to this suggestion, selecting minnows (Z. platypus) was judged to be rational in selecting a fish type that can be seen easily anywhere in Korea. This study used the fish habitat suitability index developed by J.G. Kim and J.W. Hur [11] on minnows in the downstream area of Yongdam Dam.

Table 2 shows the habitat suitability index on minnows; the channel index means the habitat index within the channel according to riverbed data. Note, however, that this study was performed based on the hydraulic experiment results on the sand riverbed; thus, this study did not consider the channel index distribution (in terms of plane) within the channel in the habitat simulation. 


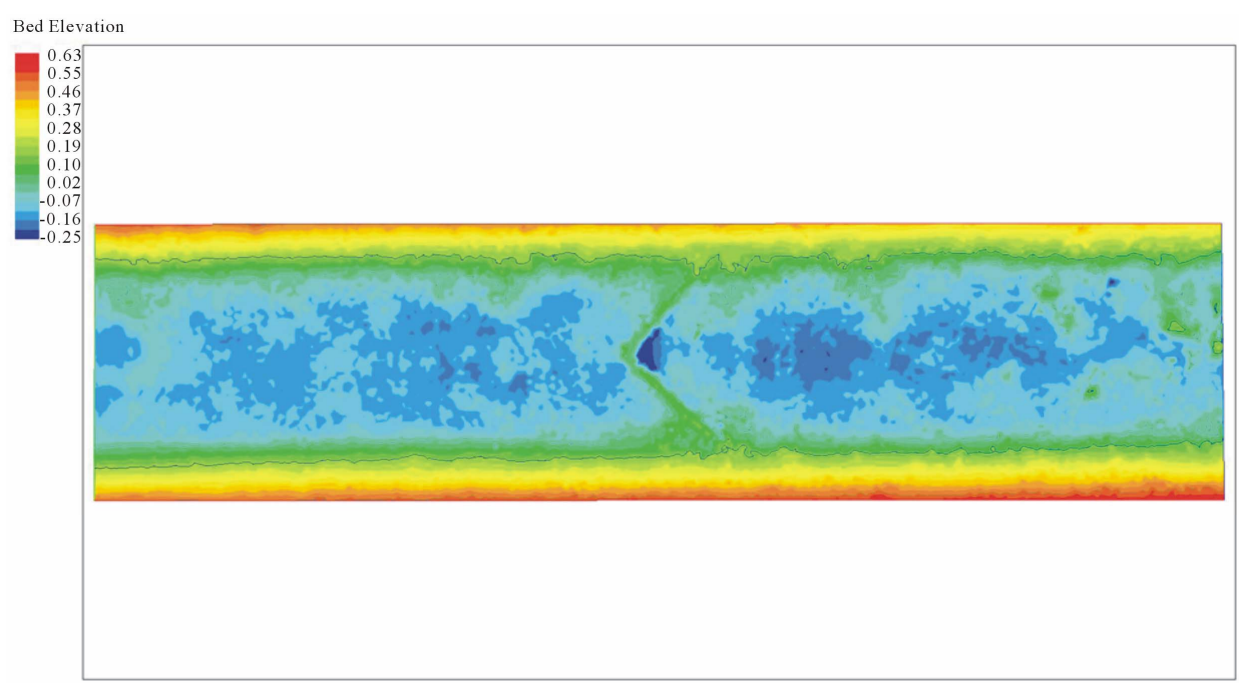

Figure 7. Bed elevation with scour from empirical equations.

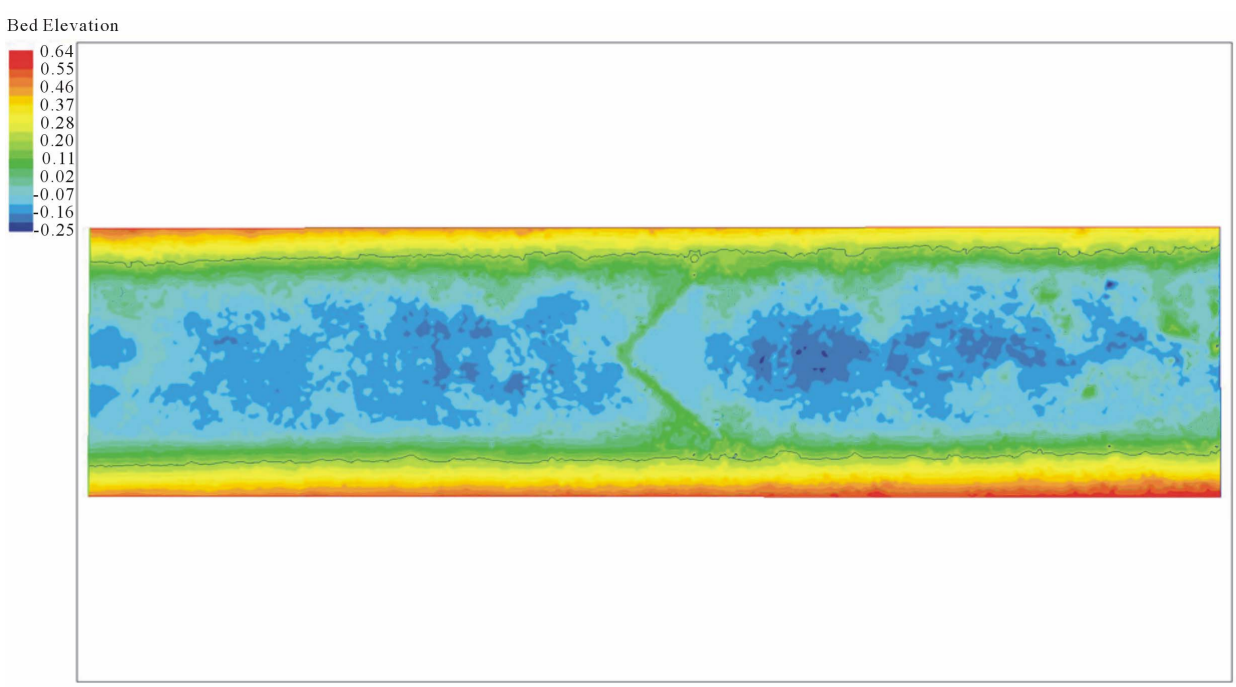

Figure 8. Bed elevation without scour from the verification test.

Table 2. HIS variations in different seasons.

\begin{tabular}{|c|c|c|c|c|c|}
\hline Species & Picture & Season (month) & Velocity $(\mathrm{m} / \mathrm{s})$ & Depth (m) & Channel Index ${ }^{1}$ \\
\hline \multirow{3}{*}{$\begin{array}{c}\text { Minnow } \\
\text { (Z. platypus) }\end{array}$} & & Spring (Apr.) & $0.1-0.5$ & $0.3-0.5$ & $3.0-4.0$ \\
\hline & & Summer (Jun.) & $0.1-0.6$ & $0.3-0.6$ & $1.0-4.0$ \\
\hline & $2 \sin 3 \cos ^{2}$ & Fall (Sep.) & $0.2-0.4$ & $0.2-0.7$ & $3.0-4.0$ \\
\hline
\end{tabular}

There may be some limitations in applying the River2D model-which was developed targeting actual channels for physical fish habitat simulation - to the experiment channel. This is because the basic factors of the River2D model are relatively not met since examination should be carried out in a state of sufficient survey data

${ }_{1}^{1} 1.0$ (silt): $>0.1 \mathrm{~mm}, 2.0$ (sand): $0.1-1.0 \mathrm{~mm}, 3.0$ (fine gravel): 1.0 $50.0 \mathrm{~mm}, 4.0$ (coarse gravel): $50.0-100.0 \mathrm{~mm}, 5.0$ (cobbles): 100.0 $300.0 \mathrm{~mm}, 6.0$ (boulder): $<300.0 \mathrm{~mm}$. where various habitat spaces such as investigation of fish species (protective species and dominant species) exist. Note, however, that this study sought to examine the scour derived from natural-type cross-cutting structure installation within the channel and the impacts on the physical habitat and present the relationship between scour downstream and habitat. Therefore, simulation targeting experiment channel was considered rational. The study was conducted under the following assump- 
tions to secure enhanced validity:

First, concerning the relationship between the weighted usable area (WUA) and flow, the topographical change data drawn through scour experiments were used rather than the existing approach of deducing the optimum flow that can provide a physical habitat to the fish species concerned as much as possible. Second, as mentioned above, channel index is uniform on the riverbed data and is decided according to the installed riverbed materials' diameters in the entire experiment channel. Third, to evaluate the impacts of the scour holes formed-due to riverbed change in the downstream area of the structure - on the habitat, the water level downstream was conditioned as outflow so that maximum scour could be formed. Based on such assumption, the habitat index change according to the scour formed in the downstream area of natural-type low drop structures was compared by applying the minnow's habitat suitability index to the scour experiment results. WUA was calculated as the total WUA calculated by grid within the length of the channel width in the downstream direction of the structure.

\section{Simulation of Habitat Evaluation}

This study analyzed the impacts of topographical change in the downstream area of the natural-type low drop structure on the habitat. Through habitat simulation, the change was investigated according to the habitat suitability index (HSI) in the downstream area of the drop structure. In Table 3, the change of HSI was categorized into with and without scour in the downstream area of the drop structure; the calculated area when deriving the index and WUA was estimated to be more than approximately $11.1 \mathrm{~m}^{2}$ in the downstream area of the drop structure. The calculation area's mean value was used for each index, and the total WUA was used in the calculation grid within the area of analysis. Figures 9-11 show the depth suitability index (DSI) distribution difference. Figures 9 and 10 show the DSI distribution when scour in the downstream area of the drop structure was considered. Figure 11 presents the distribution of DSI when scour in the downstream area of the drop structure was not considered. The DSI distribution within the channel was almost similar, but mean value of about 0.54 was recorded when scour was considered and about 0.55 when maximum scour depth was formed as a result of the analysis of only the scour area in the downstream area of the drop structure. When scour was not considered, mean value of about 0.53 was derived. Meanwhile, in the case of the points with maximum scour depth, the mean values were $0.93,1.00$, and 0.75 , respectively. According to the DSI distribution analysis, scour in the downstream area of the natural-type drop structure was confirmed to have a very positive effect on the minnow's habitat when scour was considered, compared to the case of not considering scour. The change of DSI showed the same results as the DSI comparative analysis results in the review of habitat change through habitat simulation by drop structure type in the previous chapter. For reference, the minnow's DSI is estimated to be 1.0 when depth is $0.3 \mathrm{~m}-0.6 \mathrm{~m}$. Consequently, DSI within a scour hole using the experiment result - in the case of scour in the downstream area of the drop structure-was 0.83 on the average and 0.85 on the average in the case of maximum scour depth. Meanwhile, depth was about $0.2 \mathrm{~m}$ around the structure when scour was not considered and 0.78 when scour was considered, which was a relatively low index.

Figures 12-14 show the velocity suitability index (VSI) in the downstream area of the natural-type drop

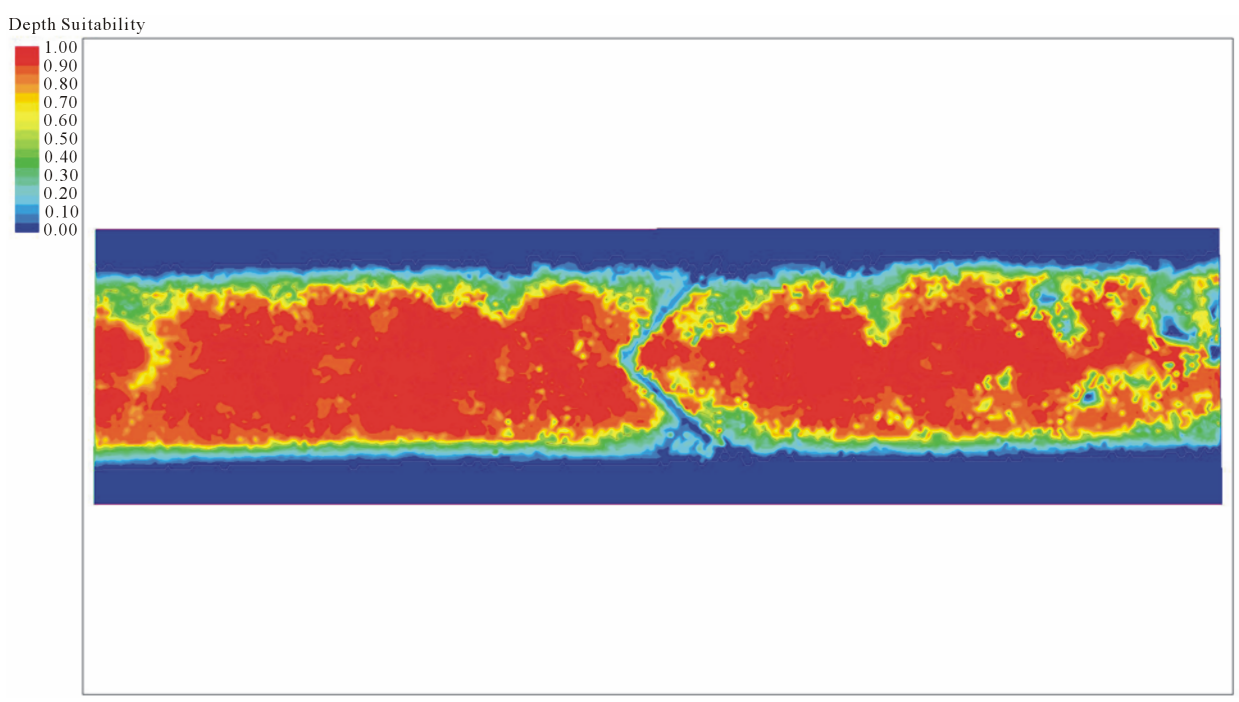

Figure 9. Distribution of DSI with scour from verification test. 


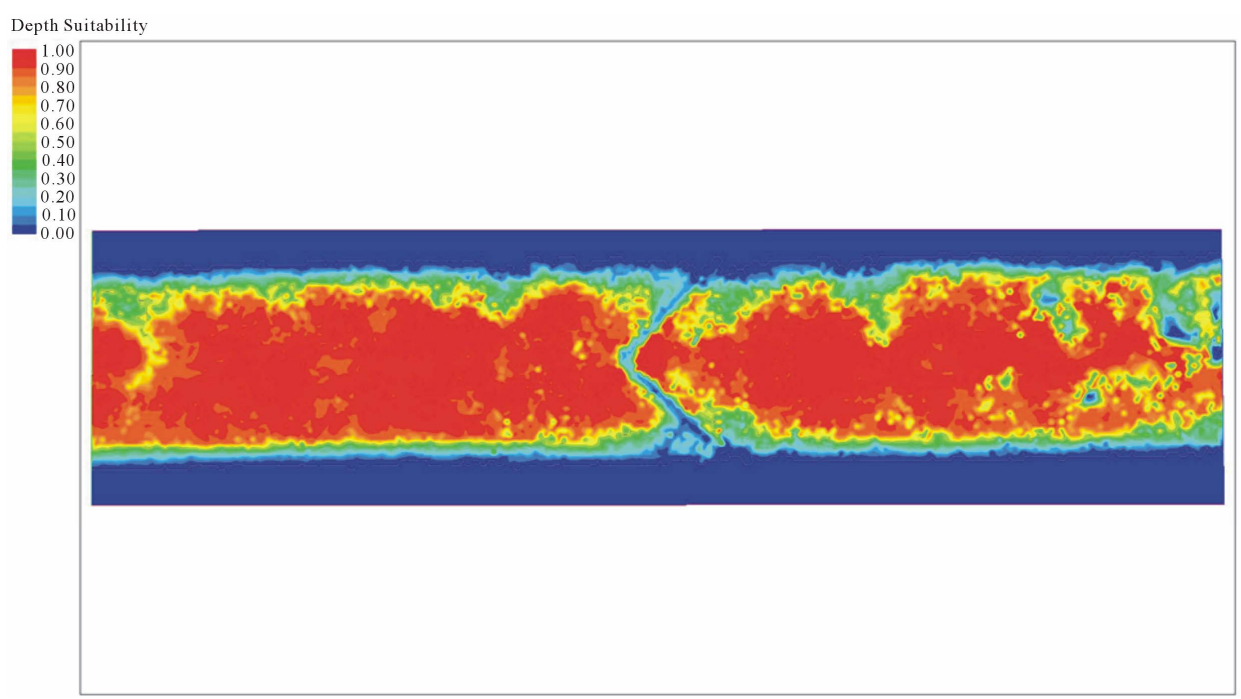

Figure 10. Distribution of DSI with scour from empirical equations.

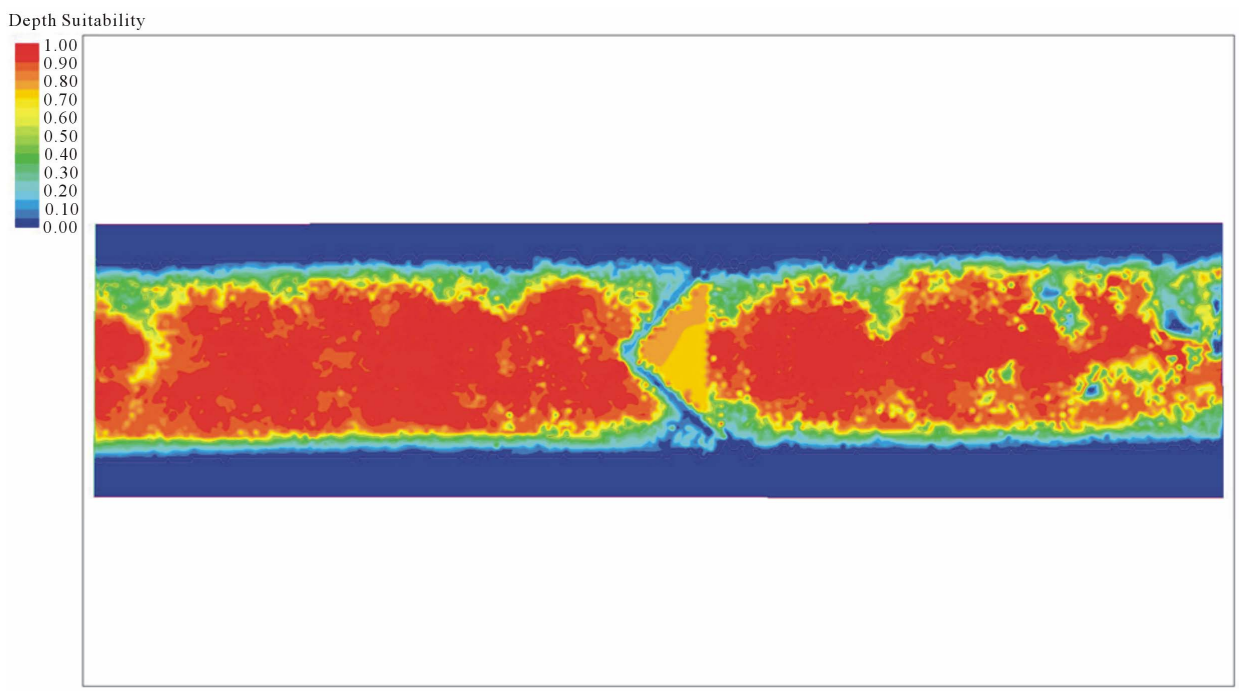

Figure 11. Distribution of DSI without scour from the verification test.

Table 3. Habitat suitability index with and without scour conditions in the downstream area of the drop structure.

\begin{tabular}{ccccc}
\hline & DSI & VSI & CSI & WUA $\left(\mathrm{m}^{2}\right)$ \\
\hline With Scour (Experimental Result) & 0.54 & 0.82 & 0.25 & 2.78 \\
With Scour (Empirical Equation) & 0.55 & 0.83 & 0.26 & 2.87 \\
Without Scour & 0.53 & 0.81 & 0.24 & 2.69 \\
\hline
\end{tabular}

structure. When scour in the downstream area of the drop structure was considered, or maximum scour depth was assumed, and when scour was not considered, the mean values of the calculation-targeted area and direct downstream area of the structure were $0.82,0.83$, and 0.81 , respectively. With regard to VSI, in case scour depth was not considered, VSI was 1.0 , but the case of not considering scour recorded the lowest value in contrast to the onsite verification result. The average index values tar- geting only the actual scour area were $0.98,0.97$, and 0.98 in the cases of considering scour, maximum scour depth, and no scour generation, respectively, implying almost similar VSI values. For high VSI distribution within a scour hole, average velocity was estimated to be about $0.3 \mathrm{~m} / \mathrm{s}$ in the downstream area of the structure; this means that average velocity of $0.3-0.6 \mathrm{~m}$ is recorded in the downstream area of the structure in the case of minnow's HSI of 1.0. As can be easily confirmed 


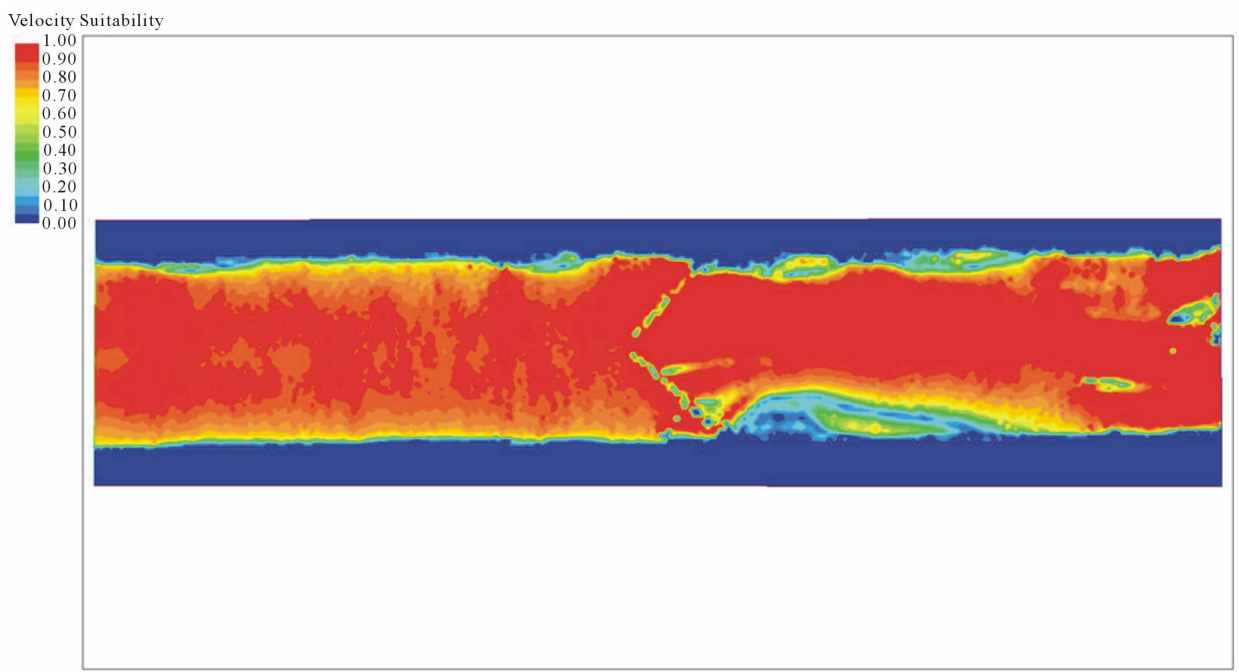

Figure 12. Distribution of VSI without scour from the verification test.

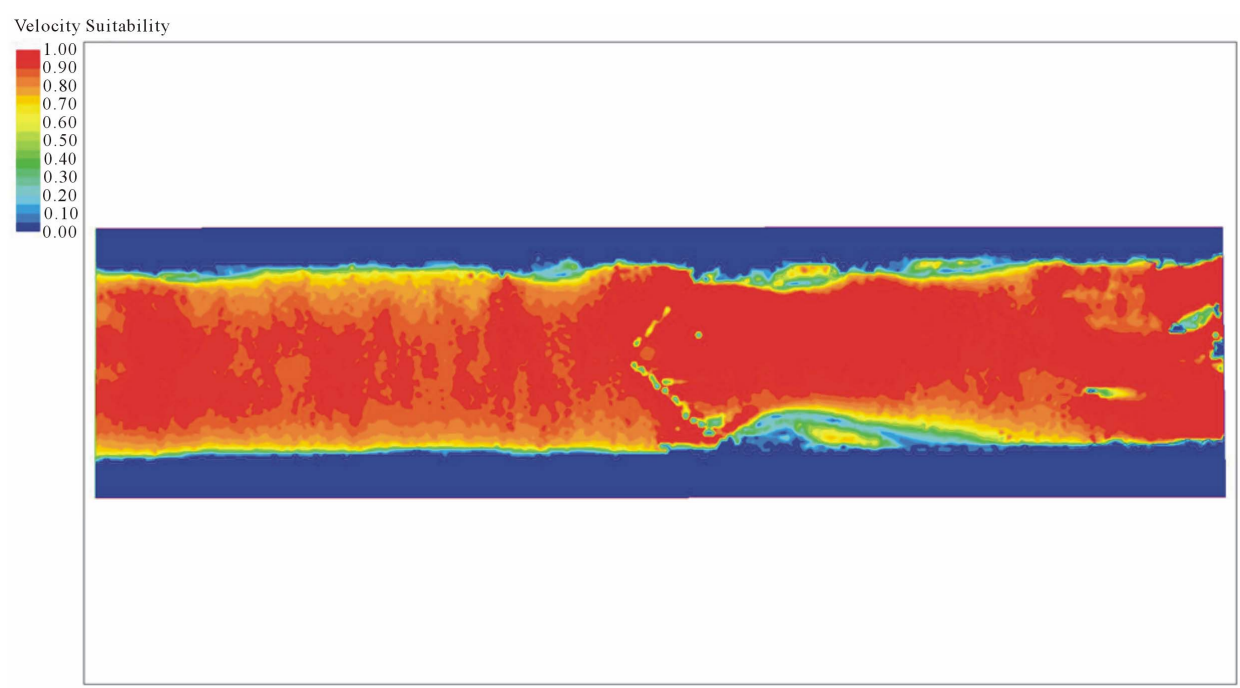

Figure 13. Distribution of VSI without scour from the verification test.

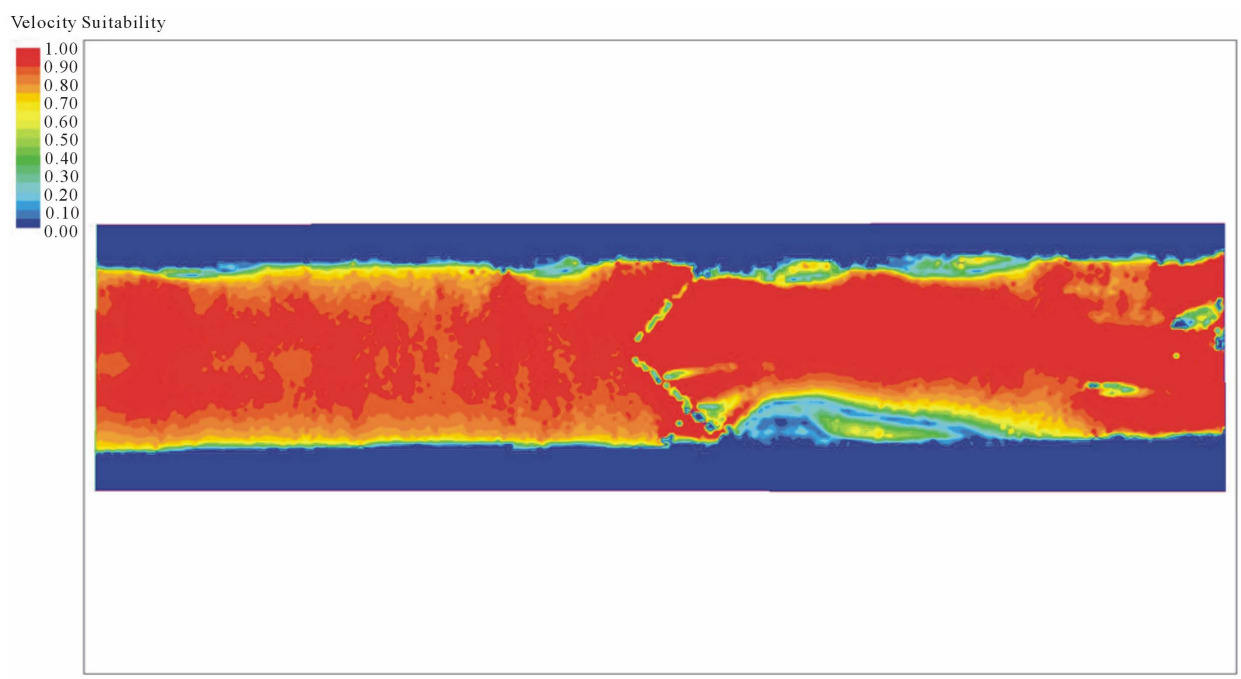

Figure 14. Distribution of VSI without scour from the verification test. 
through the figure, the velocity calculated through habitat simulation satisfied the velocity scope in the remaining area except the left and right sides of the downstream area of the structure. The difference of VSI on the left and right sides of the downstream area of the structure was derived from the channel topography. On the right side of the downstream area in particular, the suitability index was found to have decreased because of the dead water region.

The complex suitability index (CSI) was shown to be of the "DSI $\times$ VSI" type, a small-scale habitat suitable for the fish species concerned. Figure 15 shows the simulation results using the data surveyed by scoured topography after natural-type low drop structure installation. The average CSI within the $11.1 \mathrm{~m}^{2}$ analysis area was 0.25 ; when only the scoured area was reviewed, the average CSI was 0.41 . Since DSI in the scoured area in the downstream area of the structure was met, the remaining area except the scour area showed relatively low DSI. Figure 16 presents the CSI distribution in the assumption and simulation of maximum scour depth. CSI within the analysis area was 0.26 on the average and 0.42 when averaging only the scour hole area. The CSI distribution was similar to the CSI simulated with the verification test results above, confirming that there was no big difference although maximum scour depth was formed. Despite maximum scour depth of $0.09 \mathrm{~m}$ in the experiment, the depth within the scour hole was close to $0.3 \mathrm{~m}$ as the water depth condition favored by minnows. Actually, the minnow's favored depth is $0.3-0.6 \mathrm{~m}$. Thus, all DSI values will be the same in such depth scope. Velocity within the scour hole was about $0.17-0.24 \mathrm{~m} / \mathrm{s}$; as such, the habitat space meeting VSI was considered to have been formed. Figure 17 shows the CSI distribution

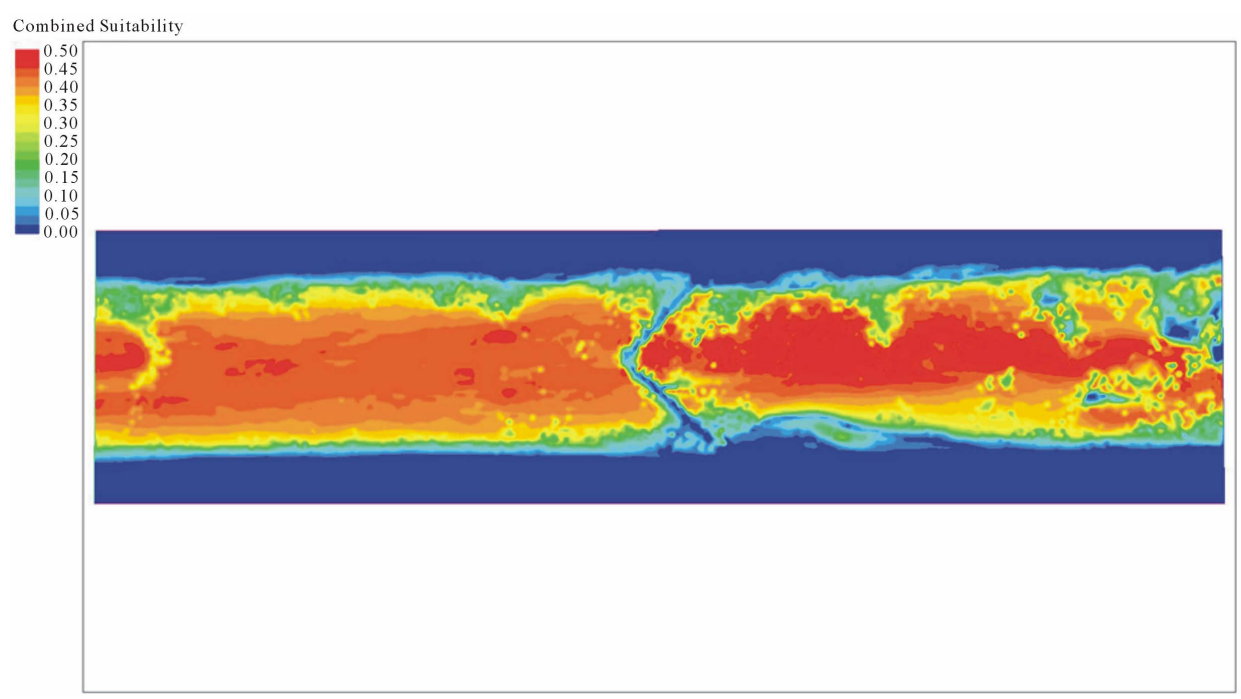

Figure 15. Distribution of CSI with scour from the verification test.

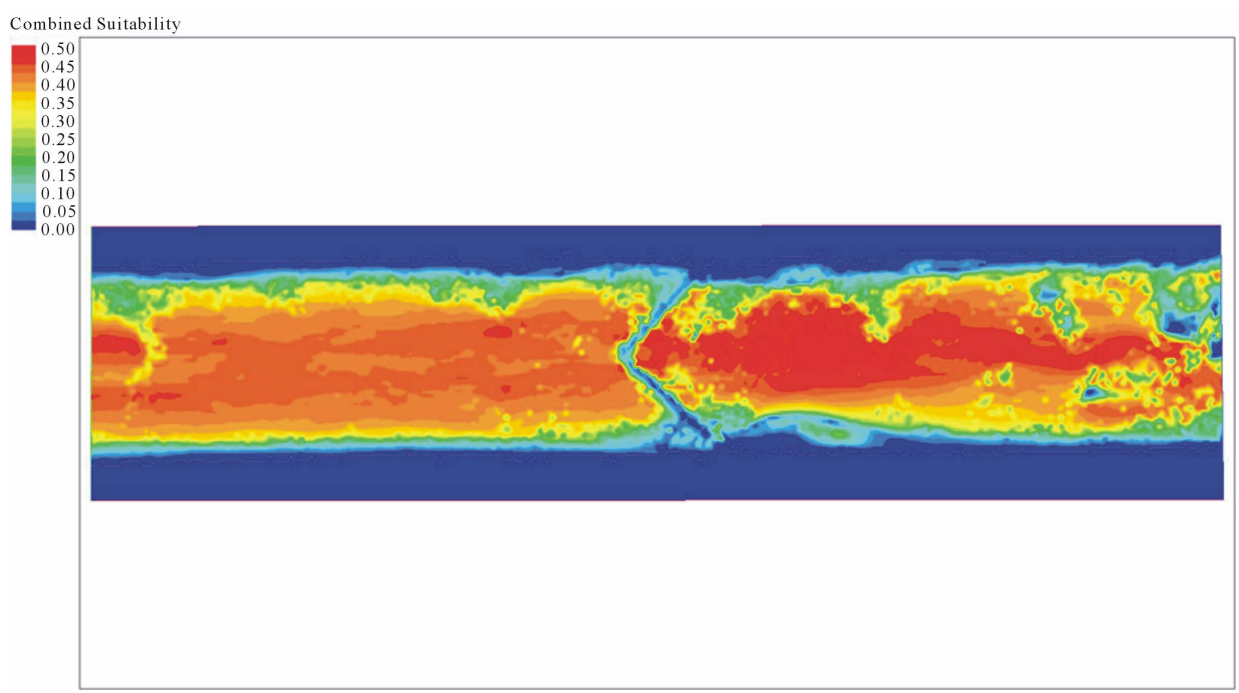

Figure 16. Distribution of CSI with scour from the empirical test. 


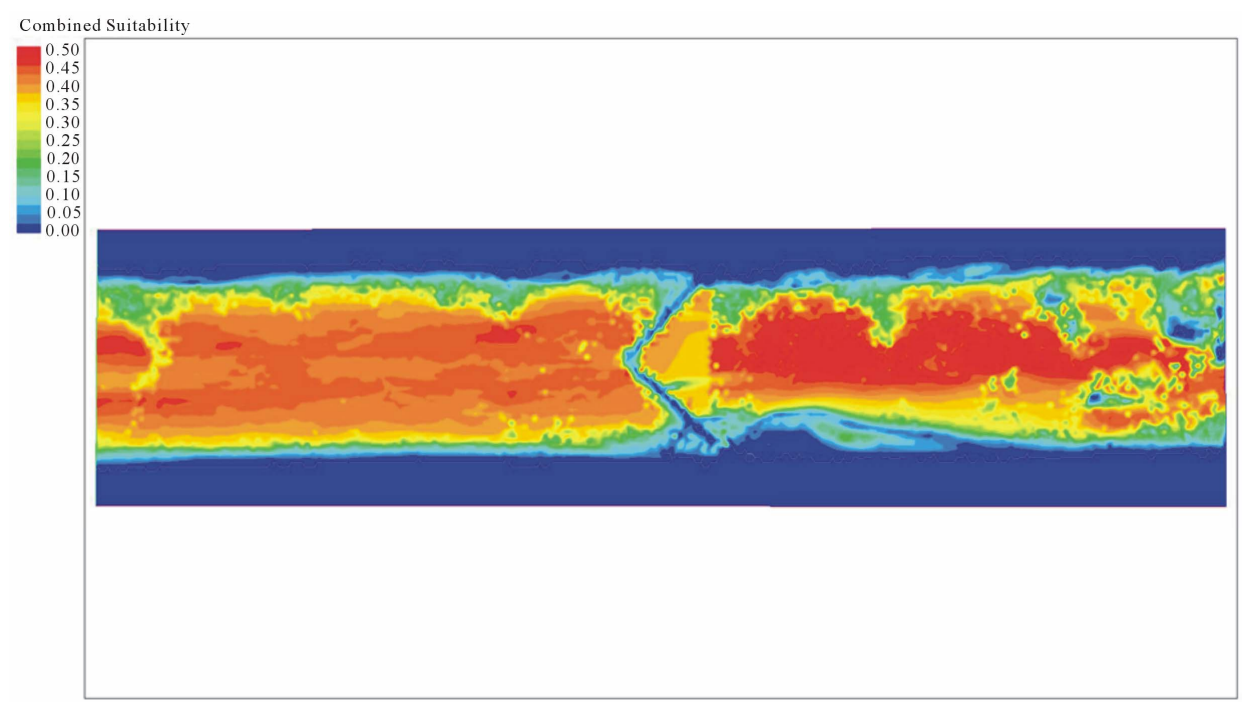

Figure 17. Distribution of CSI without scour from the verification test.

when scour in the downstream area of the drop structure was not considered. CSI within the analysis area was 0.24 on the average and 0.39 when only the scour area was averaged. Although there was no big difference between the scour considering case and maximum scour depth condition, such result was believed to be attributable to the fact that evaluation was conducted in the condition wherein the depth downstream was the minnow's favored depth. Note, however, that the average DSI in the scour area recorded up to 0.07 , and maximum difference of -0.01 was noted in terms of VSI. This means that the HSI effect is bigger than the reduction of VSI because of scour hole formation as depth increases. Based on this, scour in the downstream area of the drop structure was confirmed to provide favorable space to the minnow's habitat environment. Separately from this, scour in the downstream area of the drop structure will increase the diameter of riverbed materials within the scour hole. This is also called armoring - particles with smaller diameter within the scour hole continue to go out from the scour hole because of scouring, but particles whose diameter is greater than the threshold will remain within the scour hole, and the average diameter within the scour hole will increase. Therefore, the minnow's channel index depends on the diameter; as riverbed materials become thicker, CSI will also increase. In riverbed materials with CSI of $1.0 \mathrm{~mm}$ or less, it is calculated as "the value $\times$ each index $\times 0.5$ ". Therefore, in the case of $1.0 \mathrm{~mm}$ or more and $50 \mathrm{~mm}$ or more when multiplying 0.75 and 1.0, respectively, bigger CSIs are expected to be recorded.

As a result of WUA, the area suitable for minnows to live increase by $3.3 \%$ when scour was not considered compared to the case wherein scour was considered and by $6.7 \%$ when maximum scour depth was formed. In the case of evaluating only the scour area $\left(2.4 \mathrm{~m}^{2}\right)$, WUA was $0.88 \mathrm{~m}^{2}$ when scour was not considered and $0.95 \mathrm{~m}^{2}$ and $0.96 \mathrm{~m}^{2}$ when scour was considered and maximum scour depth was formed, respectively. When the channel index within the scour hole was considered, higher WUA difference was forecast owing to the armoring of riverbed materials or increase in diameter because of scouring. In this context, scour in the downstream area of the natural-type low drop structure was confirmed to have a positive effect on the habitat of the fish species concerned, and a structure that can meet the velocity condition favorable to the minnow's habitation could be designed.

\section{Conclusions}

This study conducted experiments on the physical change of scour according to natural low drop structure installation on the minnow's habitat environment targeting largescale artificial channel including habitat simulation.

In the habitat experiments and habitat simulation, a change of habitat suitability index (HSI) was observed, and the depth suitability index (DSI) increased due to the formation of scour holes. Nonetheless, there was some limitation owing to the difference in large-scale experiment venues and natural channels. This study actually identified the suitability of the changing habitat, because of the formation of scour holes. With the drop structure installation, this study showed that an alternative that meets not only DSI but also the velocity suitability index (VSI) can be devised.

As a result of WUA comparison, the area suitable for minnows to live increased by $3.3 \%$ and $6.7 \%$ when scour was considered unlike when scour was not considered and when maximum scour depth was formed, respectively. In the case of evaluating only the scour area (2.4 
$\mathrm{m}^{2}$ ), WUA was $0.88 \mathrm{~m}^{2}$ when scour was not considered and $0.95 \mathrm{~m}^{2}$ and $0.96 \mathrm{~m}^{2}$ when scour was considered and maximum scour depth was formed, respectively.

When a natural type-low drop structure is installed targeting a natural channel, and as monitoring is carried out in the future, precise evaluation of the habitat effect of the natural-type low drop structure is expected to be possible.

\section{Acknowledgements}

This study was supported by the Internal Research Project of "River Structure Design Techniques for Harmonizing Nature with the Human" in KICT.

\section{REFERENCES}

[1] H. J. Kim, C. W. Kim and H. S. Woo, "The Impact and Alternative of Ecological Growth with River Crossing structure," The Magazine of the Korean Society of Civil Engineers, Korean Society of Civil Engineers, Vol. 51, No. 3, 2003, pp. 42-58. (in Korean)

[2] Korea Water Resource Association, "River Design Standard," Korea Water Resource Association, 2009. (in Korean)

[3] Ministry of Environment, "Development of Close-toNature River Improvement Techniques Adapted to the Korean Streams," Korea Institute of Construction Technology, 2002. (in Korean)

[4] C. M. Cooper and S. S. Knight, "Fisheries in Man-Made Pools below Grade-Control Structures and in Naturally occurring Scour Holes of Unstable Streams," Journal of Soil and Water Conservation, Vol. 42, No. 5, 1987, pp.
370-373.

[5] Washington State Aquatic Habitat Guidelines Program, "Stream Habitat Restoration Guidelines," Washington State Department of Fish and Wildlife, 2004.

[6] D. K. Lim, S. H. Jung, H. K. Ahn and K. H. Kim, “Application of Physical Habitat Simulation System (PHABSIM) in the Reach of Small Dam Removal for Zacco platypus," Journal of Korea Water Resource Association, Korea Water Resource Association, Vol. 40, No. 11, 2007, pp. 909-920. (in Korean)

[7] P. Steffler and J. Blackburn, "River2D; Two-Dimensional Depth Averaged Model of River Hydrodynamics and Fish Habitat," University of Alberta, Edmonton, 2002.

[8] C. D. Svoboda and K. Russell, "Flume Analysis of Engineered Large Wood Structures for Scour Development and Habitat," World Environmental and Water Resources Congress 2011: Bearing Knowledge for Sustainability, Proceedings of the 2011 World Environmental and Water Resources Congress, Palm Springs, 22-26 May 2011, pp. 2572-2581.

[9] L. H. J. Christopher, "Numerical Analysis of the Performance of Rock Weirs: Effects of Structure Configuration on Local Hydraulics," World Environmental \& Water Resources Congress 2009, Kansas City, 17-21 May 2009, pp. 3244-3255.

[10] US Geological Survey, "PHABSIM for Windows; User's Manual and Exercises," Midcontinent Ecological Science Center, 2001.

[11] J. G. Kim and J. W. Hur, "The Present State of Monitoring for Estimation of Ecological Discharge and Assessment of Health in River," Magazine of Korea Water Resource Association, Korea Water Resource Association, Vol. 41, No. 10, 2008, pp. 30-35. (in Korean) 